\title{
VALORAÇÃO AMBIENTAL DE PROPRIEDADES RURAIS DE MUNICÍPIOS DA BACIA HIDROGRÁFICA DO RIO XOPOTÓ, MG
}

\author{
Mariana Barbosa Vilar ${ }^{1}$, Ana Carolina Campanha de Oliveira², Laércio Antônio Gonçalves Jacovine \\ Matheus Garcia Ferreira ${ }^{4}$, Agostinho Lopes Souza ${ }^{3}$
}

(recebido: 15 de maio de 2009; aceito: 30 de agosto de 2010)

\begin{abstract}
RESUMO: Os estudos da economia ambiental baseiam-se no entendimento de que a conservação e as melhorias ambientais podem ser viabilizadas por meio da utilização de instrumentos econômicos. Entretanto, para utilização destes, é necessário conhecer o valor econômico do meio ambiente. Assim, os valores dos recursos ambientais podem ser estimados, por meio do conhecimento da disposição da sociedade a pagar pela preservação dos recursos e serviços ambientais. Dentro dessa perspectiva, realizou-se um diagnóstico socioeconômico e ambiental na Bacia Hidrográfica do Rio Xopotó com o intuito de estimar o valor ambiental de 40 propriedades rurais distribuídas em quatro municípios dessa bacia. Por meio da adaptação da metodologia da Disposição a Pagar estimou-se a Disposição a Receber (DAR) de cada produtor rural para imobilizar áreas em suas propriedades de forma que essas garantissem a provisão de serviços ambientais. A Bacia Hidrográfica do Rio Xopotó vem sofrendo grandes pressões antrópicas que comprometem a promoção dos serviços ambientais. O valor da DAR revelado pelos produtores rurais para que eles destinem parte de sua propriedade para a conservação ambiental, corresponde, em média, a $\mathrm{R} \$ 160,00$.(ha.ano) ${ }^{-1}$. Esse valor se aproxima do que já é praticado em algumas iniciativas de pagamento por serviços ambientais em alguns municípios brasileiros. $\mathrm{O}$ resultado encontrado pode ser considerado um balizador para a tomada de decisões e elaboração de políticas públicas que reconheçam os agricultores como produtores de serviços ambientais, incentivando-os a continuarem prestando estes serviços fundamentais à sobrevivência humana.
\end{abstract}

Palavras-chave: Economia ambiental, serviços ambientais, compensação ambiental.

\section{ENVIRONMENTAL VALUATION OF FARMS OF THE XOPOTÓ RIVER WATERSHED COUNTIES, MG}

\begin{abstract}
The studies of environmental economy are based on the understanding that environmental conservation and improvements can be executed through the use of economic instruments. However, to use these instruments, it is necessary to understand the economic value of the environment. The environmental resources and services values can be estimated by the knowledge of the society willingness to pay (WTP) for their preservation. Inside of this perspective, a socioeconomic and environmental diagnosis was accomplished on the Xopotó River Watershed. The diagnosis aimed at estimating the environmental value of 40 farms distributed in four counties of this watershed. Through the adaptation of the Willingness to Pay (WTP) methodology, the Willingness to Receive (WTR) of each farmer to immobilize areas in their farms to ensure the provision of environmental services was estimated. The Xopotó River Watershed is undergoing great pressures that endanger the promotion of environmental services. The value of the WTR revealed by the farmers to maintain preserved areas of important environmental functions in their farms corresponds, on average, to $R \$ 160,00$. (ha.year) ${ }^{-1}$. This value is closed to that one which is already practiced in some payment for environmental services initiatives in Brazil. This value serve as reference for implementation of public policies, which would recognize the farmers as environmental services producers, motivating them to continue exercising these services for the human survival.
\end{abstract}

Key words: Environmental economy, environmental services, environmental compensation.

\section{INTRODUÇÃO}

A utilização de métodos participativos para entender e avaliar situações rurais e para planejar o desenvolvimento de comunidades torna-se uma importante ferramenta para o manejo dos recursos naturais e para o desenvolvimento rural sustentável (COELHO, 2005).
Segundo Marques \& Comune (1997) é necessário valorar corretamente os bens e serviços do meio ambiente, entendidos no desempenho de suas funções (provisão de matérias-primas, capacidade de assimilação de resíduos, estética e recreação, biodiversidade, regulação dos ciclos naturais) para se integrar esses valores, apropriadamente estimados, às decisões sobre

\footnotetext{
${ }^{1}$ Engenheira Florestal, Mestre em Ciências Florestais - Departamento de Engenharia Florestal/DEF - Universidade Federal de Viçosa/ UFV - 36570-000 - Viçosa, MG - maribvilar@hotmail.com

${ }^{2}$ Engenheira Florestal - Universidade Federal de Viçosa/UFV - 36570-000 - Viçosa, MG - carolviflo@yahoo.com.br ${ }^{3}$ Engenheiro Florestal, Professor Doutor em Ciências Florestais - Departamento de Engenharia Florestal/DEF - Universidade Federal de Viçosa/UFV - 36570-000 - Viçosa, MG - jacovine@ufv.br, alsouzaal@gmail.com

${ }^{4}$ Graduando em Engenharia Florestal - Departamento de Engenharia Florestal/DEF - Universidade Federal de Viçosa/UFV - 36570-000 Viçosa, MG - matheusgf85@yahoo.com.br
} 
a política econômica e ambiental e aos cálculos das contas econômicas nacionais.

Contudo, é preciso enfatizar que a simples valoração está distante de caracterizar-se como intervenção política de reorientação das práticas de uso social dos recursos naturais. Essa intervenção política deve ser resultado do planejamento integrado da gestão dos recursos naturais com os anseios de desenvolvimento das forças sociais estabelecidas num dado território. Isso significa dizer que a gestão ambiental é componente indissociável das estratégias de desenvolvimento social, e estas, devem ser condicionadas pelas necessidades de equilíbrio dos ecossistemas naturais (MARTINS \& VALENCIO, 2003).

O estabelecimento de políticas de controle ambiental segue o princípio do Poluidor Pagador (PPP), que define que o poluidor deverá arcar com os custos das medidas para redução da poluição, decididas pelas autoridades públicas para assegurar que o meio ambiente se encontre em estado aceitável. Atualmente, no Brasil, sabe-se que as políticas de comando controle são ineficientes para garantir a preservação ambiental. A compensação por serviços ambientais surge como forma de incentivar o produtor rural a proteger áreas de importantes funções ecossistêmicas dentro de sua propriedade. Define-se, desta forma, o princípio do Conservador Recebedor onde aquele que conserva recebe algum incentivo ou, até mesmo, remuneração para proteger determinadas áreas. Diante disso, é necessário realizar estudos que possam balizar as políticas públicas para a implementação do pagamento por serviços ambientais. Assim, neste trabalho, objetivou-se caracterizar ambientalmente propriedades rurais da Bacia Hidrográfica do Rio Xopotó e promover a valoração destas áreas como base para o estabelecimento de instrumentos econômicos de incentivo aos produtores rurais que conservam recursos naturais garantindo suas funções ambientais.

\section{MATERIAL E MÉTODOS}

\subsection{Descrição da área de estudo}

A Bacia Hidrográfica do Rio Xopotó está inserida na cabeceira da Bacia Hidrográfica do Rio Doce, sendo classificada como uma sub-bacia. A bacia do Rio Doce é considerada uma das mais importantes do Estado de Minas Gerais e se localiza na Região Hidrográfica Costeira do Sudeste (AGÊNCIA NACIONAL DE ÁGUAS - ANA, 2009). A Bacia Hidrográfica do Rio Xopotó está inserida no Bioma Mata Atlântica, sendo quase totalmente coberta por Florestas Estacionais Semideciduais. Possui altíssima diversidade biológica, abrigando significativa proporção de espécies endêmicas (COMITÊ DA BACIA HIDROGRÁFICA DO RIO DOCE - CBH RIO DOCE, 2005). Os principais afluentes do Rio Xopotó se encontram nos municípios de Senhora dos Remédios, Rio Espera, Dores do Turvo, Divinésia e Senhora de Oliveira (Figura 1).

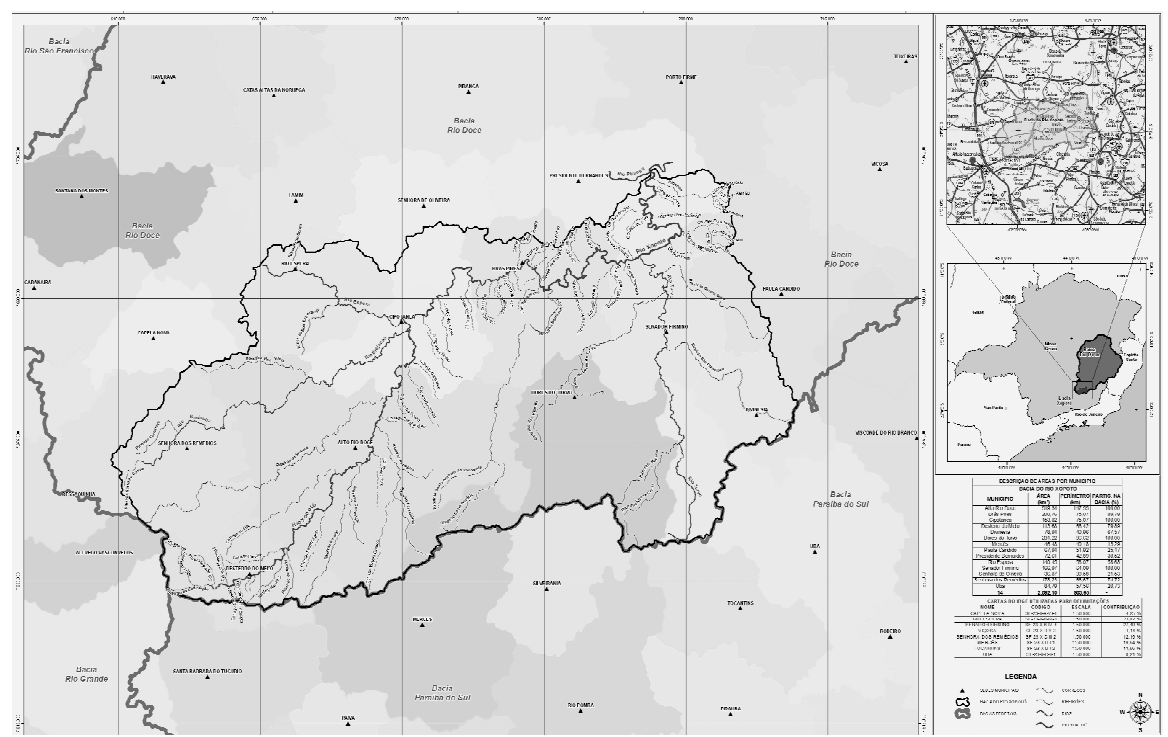

Figura 1 - Limite da Bacia Hidrográfica do Rio Xopotó e Mapa de Minas Gerais com detalhe para a Bacia do Rio Doce (Adaptado de INSTITUTO MINEIRO DE GESTÃO DAS ÁGUAS - IGAM, 2008).

Figure 1 - Limit of Xopotó River Watershed and Map of Minas Gerais with detail for Doce River Watershed (Adapted from INSTITUTO MINEIRO DE GESTÃO DAS ÁGUAS - IGAM, 2008).

Cerne, Lavras, v. 16, n. 4, p. 539-545, out./dez. 2010 


\subsection{Técnicas de Diagnóstico Rápido Participativo}

Os métodos de diagnóstico rural permitem não só identificar os recursos existentes em nível local, mas também perceber como os interesses sócioambientais se estruturam e se articulam naquele espaço. Para efetivação da caracterização ambiental da região de estudo buscouse, por meio do diagnóstico, identificar os principais atributos do grupo social com o qual se trabalhou (COELHO, 2005).

Dentro desta lógica, para definição da amostra, solicitou-se a entidades locais (Prefeitura, Emater-MG, Sindicatos, entre outras) que indicassem, com base no conhecimento e entendimento da realidade local, produtores rurais que representassem a zona rural do município. Destas indicações, aqueles produtores que tiveram disponibilidade de receber a equipe de pesquisadores e participar da pesquisa foram incluídos na amostra. Esta foi composta por 40 produtores rurais, sendo dez em cada um dos municípios (Alto Rio Doce, Brás Pires, Cipotânea, e Desterro do Melo). A fim de conhecer a realidade local e de levantar potencialidades e demandas da população pesquisada foram aplicados 40 questionários socioeconômicos e ambientais.

Para avaliação ambiental das propriedades rurais utilizou-se a técnica de diagnóstico rápido participativo denominada caminhamento transversal também utilizada por Lopes \& Casalinho (2007). Essa técnica consistiu em percorrer a propriedade rural junto do proprietário, buscando coletar informações sobre o ambiente, seu histórico e utilização. No questionário foram levantadas questões que seguiram o seguinte roteiro:

I - Perfil social: dados pessoais, profissão, fonte de renda.

II - Caracterização da família do produtor: informações sobre os membros da família que residem na propriedade (idade, escolaridade e profissão).

III - Localização da propriedade: dados da propriedade e georreferenciamento da sede.

IV - Caracterização da propriedade: caracterização agropecuária, tecnologias adotadas, assistência técnica e organização comunitária.

V - Caracterização ambiental: identificação e caracterização das áreas de reserva legal (RL) e Áreas de Preservação Permanente (APP); classificação dos estágios sucessionais das matas encontradas com base na Resolução No 392/2007 do CONAMA; identificação e caracterização dos recursos hídricos; identificação de áreas degradadas; verificação das práticas conservacionistas que são adotadas em cada propriedade e classificação do estado de conservação das APPS em três categorias, segundo Pinto et al. (2004): i. Conservada - apresenta vegetação natural em estágio sucessional médio ou avançado; ausência de áreas degradadas ou erodidas; solo sem compactação; recursos hídricos protegidos contra o pisoteio de animais. ii. Perturbada - vegetação nativa em estágio inicial de sucessão; presença de culturas com manejo de baixo impacto; poucas áreas com exposição do solo; início de erosão laminar; presença de indicadores de regeneração natural. iii. Degradada - ausência de vegetação; alto grau de perturbação; presença de animais pisoteando e contaminando os recursos hídricos; áreas erodidas (sulcos ou voçorocas) e compactadas.

\subsection{Técnicas de valoração econômica de recursos naturais}

Métodos indiretos de valoração econômica são aplicados quando um determinado elemento do ecossistema não pode ser valorado pelo comportamento do mercado. Quando mercados para bens e serviços ambientais não existem, ou não existem mercados alternativos para se proporem substituições, há a necessidade de se aplicarem métodos de valoração contingentes, isto é, com certo grau de incerteza. Esses métodos são aplicados para valorar elementos da natureza (biodiversidade, patrimônio paisagístico, áreas de proteção ambiental, áreas de lazer) ou qualquer outra situação na qual não existam valores de mercado (MATTOS et al., 2005).

Segundo Harrison (2006), os métodos mais populares de valoração ambiental envolvem uma pesquisa hipotética. O método de valoração contingente busca, por meio de surveys (entrevistas pessoais), revelar as preferências dos indivíduos por um bem ou serviço ambiental; consequentemente, busca captar o valor que um consumidor estaria disposto a pagar pelo aproveitamento de um bem natural (qualidade do ar, da água, etc.) (SILVA \& LIMA, 2004). A adaptação dessa metodologia resultou na Disposição a Receber (DAR) que permitiu que fosse perguntado ao produtor rural o quanto ele estaria disposto a receber para imobilizar determinadas áreas em sua propriedade para garantir a provisão de serviços ambientais. A utilização da técnica da DAR se justifica pela possibilidade de verificar o quanto o produtor rural estaria disposto a receber pelo pagamento por serviços ambientais. Foram utilizadas enquetes para identificar o valor de uso que as pessoas dão à preservação de determinadas áreas dentro de suas propriedades e quanto estariam dispostas a receber (por hectare, por ano) para

Cerne, Lavras, v. 16, n. 4, p. 539-545, out./dez. 2010 
manter essas áreas de preservação. A técnica de eliciação utilizada para determinar a DAR foi uma adaptação do método referendum com jogos de leilão, adaptado de Mattos et al. (2007). Foram oferecidos lances iniciais, conforme critérios pré-estabelecidos. Esses valores resultaram de consultas a especialistas da área, revisões de literatura e se basearam no rendimento da atividade pecuária na região, buscando captar o quanto que, em uma análise prévia, era consenso que o produtor estaria disposto a receber para preservar áreas de preservação permanente. Caso o valor inicial proposto não fosse aceito, aumentava-se o lance até obter uma resposta positiva. Vale ressaltar que as distorções do mercado imperfeito e as questões de distribuição de renda podem gerar dados não tangíveis.

\section{RESULTADOS E DISCUSSÃO}

\subsection{Diagnóstico Sócio-Econômico e Ambiental}

Foram cadastradas 40 famílias, com média de 4,0 membros por família, totalizando 162 pessoas envolvidas direta ou indiretamente no diagnóstico. Desse total, 56,8\% são homens e 43,2\% são mulheres. A grande maioria dos chefes de família entrevistados $(84 \%)$ possui como profissão a atividade rural. A fonte de renda mais significativa para $70 \%$ dos produtores rurais envolvidos no diagnóstico é proveniente da atividade rural. A maior parte das propriedades visitadas, 37,5\%, apresenta área variando entre 40 e 150 ha; $32,5 \%$ possuem área de 10 a 40 ha; $22,5 \%$ apresentam área menor que 10 ha; e 7,5\% possuem área com mais de 150 hectares.

As principais atividades desenvolvidas para subsistência e comercialização estão ilustradas na Figura 2. Verifica-se que a fonte principal de renda nessa região é a pecuária leiteira. As principais atividades desenvolvidas para subsistência são os cultivos de cana, milho, feijão, hortaliças, fruticultura e atividades pecuárias. $\mathrm{O}$ cultivo de cana é praticado por $87,5 \%$ dos produtores rurais, sendo que a produção é utilizada principalmente para alimentação de bovinos. Atualmente, poucos produtores utilizam a cana para alimentação humana, sendo esta uma antiga tradição da cultura rural que se perdeu com a introdução de novos hábitos alimentares.

Nos municípios estudados apenas $35 \%$ dos produtores entrevistados possuem áreas de Reserva Legal (RL) em suas propriedades, sendo que apenas 5\% destes averbaram suas reservas. Em 100\% das propriedades visitadas foram encontradas Áreas de Preservação Permanente (APPs) e estas foram classificadas em mata ciliar, entorno de nascente, topo de morro, várzea e área com declividade superior a $100 \%$. Os estágios inicial e médio de sucessão da vegetação

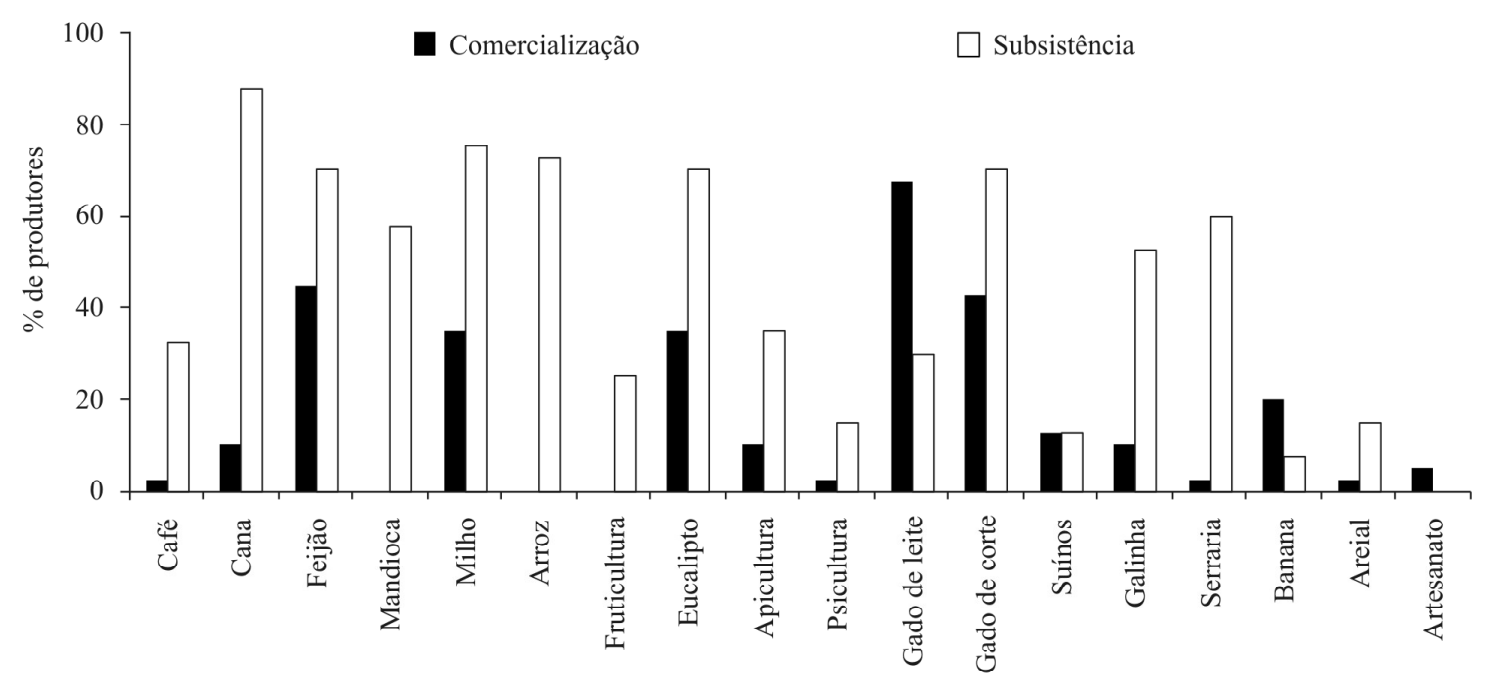

Atividades desenvolvidas

Figura 2 - Principais atividades rurais de subsistência e comercialização desenvolvidas nas propriedades rurais da Bacia Hidrográfica do Rio Xopotó, MG. Julho de 2008.

Figure 2 - Main rural activities developed for subsistence and commercialization on farms of the Xopotó River Watershed, MG. July 2008.

Cerne, Lavras, v. 16, n. 4, p. 539-545, out./dez. 2010 
secundária predominaram nas APPs ocupadas com mata nativa (Figura 3). Prevaleceu em todos os tipos de APPs, o estado de conservação perturbado, caracterizando $66 \%$ destas áreas. Apenas $12 \%$ das APPs foram classificadas como conservadas e $22 \%$ como degradadas (Figura 4 ).

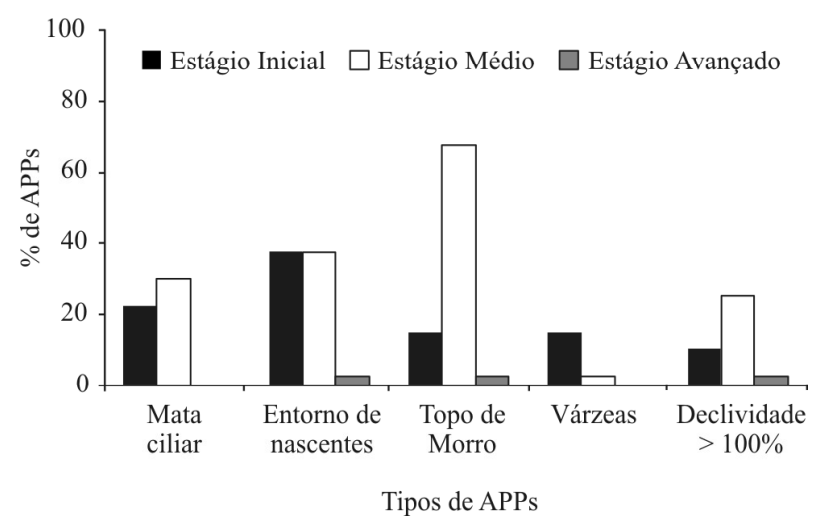

Figura 3 - Distribuição dos estágios sucessionais das áreas de mata nativa das APPs visitadas na Bacia Hidrográfica do Rio Xopotó, MG. Julho de 2008.

Figure 3 - Distribution of succession stages of areas with native forest found on APPs visited on the Xopotó River Watershed, MG. July 2008.

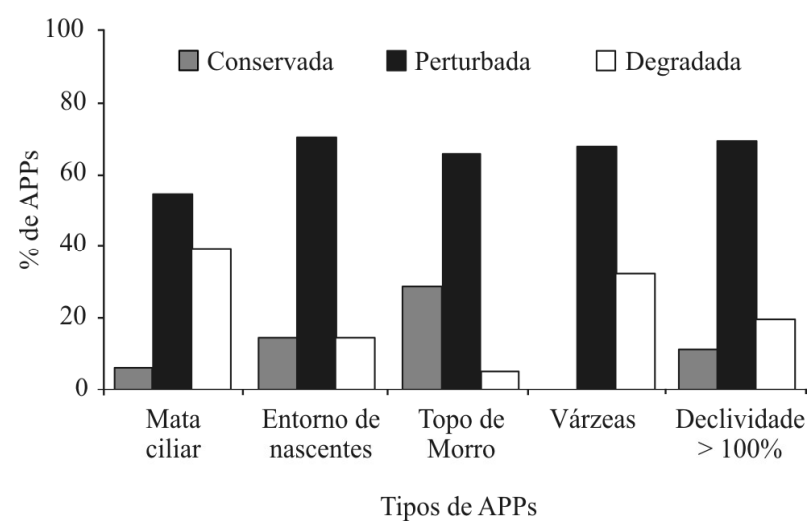

Figura 4 - Estado de conservação das APPs encontradas nas propriedades rurais visitadas na Bacia Hidrográfica do Rio Xopotó, MG. Julho de 2008.

Figure 4-Conservation state of APPs found on farms visited on the Xopotó River Watershed, MG. July 2008.

Observou-se que $100 \%$ das propriedades visitadas possuem recursos hídricos: nascentes (87\%); córregos ou ribeirões (90\%); represas, barragens e/ou açudes (37\%) e rios que passam dentro dos limites da propriedade (25\%).
Em nenhuma das 40 propriedades visitadas os recursos hídricos se classificaram como conservados. Isso pode ser explicado pela ausência de fossa séptica e pelo lançamento de todos os resíduos das propriedades nos corpos d' água. Essa é uma necessidade básica que não é atendida na zona rural e, portanto, é motivo de contaminação da água e geração de doenças. Segundo IGAM (2008), o Índice de Qualidade das Águas (IQA) do rio Xopotó, monitorado próximo à sua foz no rio Piranga, apresentou-se no estado médio em 2007. A contagem de coliformes termotolerantes estava acima do limite estabelecido na legislação ambiental, em razão do despejo de efluentes sanitários dos municípios de Desterro do Melo, Alto Rio Doce, Cipotânea, Brás Pires e Senador Firmino.

A maior parte dos produtores envolvidos no diagnóstico não utiliza nenhuma técnica de conservação do solo em suas práticas agrícolas. No entanto, quando utilizadas, as principais técnicas conservacionistas foram o plantio direto, plantio em nível, rotação de culturas e curvas de nível.

\subsection{Valoração Econômica dos Recursos Naturais}

A valoração econômica dos recursos naturais presentes na propriedade foi obtida com base no valor que o produtor rural estaria Disposto a Receber (DAR) para manter preservadas áreas de importantes funções ambientais em sua propriedade. Considerando os valores sugeridos que variaram de $\mathrm{R} \$ 100,00$ a $\mathrm{R} \$ 340,00$.(ha.ano) ${ }^{-1}$, obteve-se uma média ponderada de $\mathrm{R} \$ 160,00$.(ha.ano) ${ }^{-1}$. Essa quantia pode ser entendida como o valor que o produtor deveria receber como compensação por não utilizar a área e o valor mínimo dos serviços ambientais. Para cálculo da média foram desconsiderados os produtores que não responderam à pergunta $(28 \%)$ e aqueles que responderam valores superiores à $\mathrm{R} \$ 340,00$ (20\%), pois, na grande maioria, os valores citados foram exorbitantes e seguiram o pensamento do "quanto mais melhor". Na Figura 5 , ilustra-se a disposição a receber sugerida pelos 40 produtores visitados. A média encontrada se aproxima ao valor utilizado em Extrema-MG no programa "Conservador das Águas", cujo pagamento é efetuado de acordo com o alcance de metas pré-estabelecidas. Nesse município, o produtor rural, prestador de serviços ambientais é remunerado em R $\$ 159,00$.(ha.ano) ${ }^{-1}$ (EXTREMA, 2005).

É interessante observar que alguns produtores fizeram uma correlação com o custo de oportunidade da terra e o valor a receber foi comparado principalmente com o valor cobrado para aluguel de pasto ( $\mathrm{R} \$ 20,00$.cabeça de gado.mês $\left.\mathrm{s}^{-1}\right)$. 


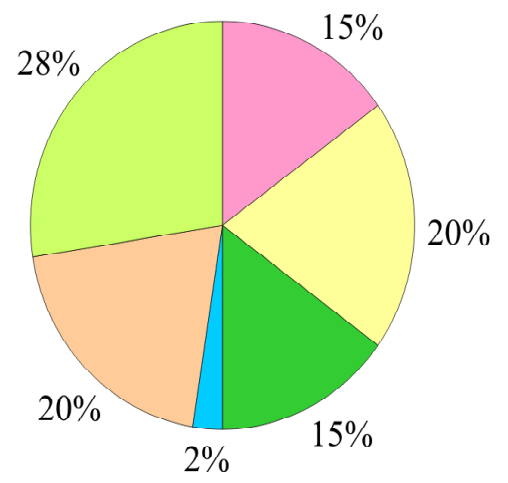

Figura 5 - Disposição a receber (DAR) manifestada por produtores rurais da Bacia Hidrográfica do Rio Xopotó, MG. Julho de 2008.

Figure 5 - Willingness to Receive (WTR) manifested by farmers from the Xopotó River Watershed, MG. July 2008.

Seguindo a lógica do custo de oportunidade da terra, percebe-se que a média ponderada da DAR foi superior ao valor de R $\$ 129,55$.(ha.ano) ${ }^{-1}$ encontrado por Côrrea (2006) e que significa a receita média que o produtor deixa de auferir para cada hectare efetivado com APP ou reserva lega na região da Zona da Mata mineira. Portanto, acreditase que o valor do custo de oportunidade da terra seja o mínimo que o produtor rural deveria receber para garantir a conservação e provisão dos serviços ambientais. Entretanto, esse valor não representa todos os valores associados aos bens e serviços ambientais. Segundo Mattos et al. (2007), um estudo de valoração ambiental de APPs da microbacia do córrego São Bartolomeu (Viçosa, MG), demonstrou, por meio da técnica da disposição a pagar, que a maioria dos viçosenses acha que proprietários rurais devem receber algum tipo de incentivo econômico para recuperar e ou preservar suas APPs. Além disso, a população entrevistada por estes autores espera que este incentivo econômico seja pago pelo governo.

\section{CONCLUSÕES}

A região da Bacia Hidrográfica do Rio Xopotó tem grandes potencialidades, em razão da riqueza de recursos naturais e beleza cênica. Os recursos hídricos são abundantes e é uma região extremamente importante para a Bacia Hidrográfica do Rio Doce, abrigando suas principais nascentes. Portanto, a sistematização dos dados coletados é de suma importância para a criação de parcerias institucionais na busca de melhorias a fim de deixar o homem do campo mais assistido e mais capacitado de conhecimentos. Além disso, o reconhecimento desses agricultores como produtores de serviços ambientais, incentiva e valoriza o homem do campo.

O valor da disposição a receber revelado pelos proprietários rurais para que eles destinem parte de sua propriedade rural para a conservação ambiental, corresponde, em média, a R \$160,00.(ha.ano) ${ }^{-1}$. Esse valor se aproxima do que já é praticado em algumas iniciativas de pagamento por serviços ambientais em alguns municípios brasileiros. A quantia encontrada pode ser entendida como o valor que o produtor rural deveria ser compensado e o valor mínimo dos serviços ambientais, baseado na disposição a receber revelada pelo produtor rural. Assim, esse valor serve de referência para implantação de políticas públicas que reconheçam e incentivem produtores rurais que conservam áreas de importantes funções ambientais em suas propriedades.

Nenhum produtor envolvido no diagnóstico recebe incentivos para garantir a provisão dos serviços ecossistêmicos. Pelo contrário, eles temem a legislação ambiental e estão inseridos em um conjunto de políticas de comando controle que, além de ineficientes, são muitas vezes intangíveis. O processo de compensação ou pagamento por serviços ambientais pode ser útil para promover a conservação ambiental e a inclusão social, visto que cada produtor se sentirá parte do processo de transformação da realidade, cumprindo com seus deveres e entendendo o seu papel como cidadão.

\section{AGRADECIMENTOS}

Ao Instituto Xopotó, principalmente ao Sr. José Geraldo Rivelli pelo empenho em desenvolver o "Projeto Agente Ambiental", e por confiar a esta equipe a missão de desenvolver o diagnóstico inicial da região. Ao IEF-MG pelo apoio. Ao CNPq pelo financiamento da pesquisa e bolsa de produtividade. $\mathrm{E}$ aos produtores rurais que receberam a equipe e acreditaram na proposta deste trabalho.

\section{REFERÊNCIAS BIBLIOGRÁFICAS}

AGÊNCIA NACIONAL DE ÁGUAS. Divisão hidrográfica nacional. Disponível em: $\langle$ http:///www.ana.gov.br̀. Acesso em: 20 jan. 2009.

\footnotetext{
*Projeto Agente Ambiental - produtor rural prestador de serviços ambientais realizado pelo Instituto Xopotó, em parceria com a Universidade Federal de Viçosa, com apoio do Instituto Estadual de Florestas (IEF-MG), por meio da Associação dos Produtores Florestais do Sudoeste de Minas Gerais (APFLOR).
} 
COELHO, F. M. G. A arte das orientações técnicas no campo: concepções e métodos. Viçosa, MG: UFV, 2005. 139 p.

COMITÊ DA BACIA HIDROGRÁFICA DO RIO DOCE. Diagnóstico consolidado da bacia. 2005. Disponível em: 4www.riodoce.cbh.gov.br/?. Acesso em: 10 mar. 2009.

CÔRREA, J. B. L. Quantificação das áreas de preservação permanente e reserva legal e de seus impactos na bacia do Rio Pomba em Minas Gerais. 2006. 79 f. Dissertação (Mestrado em Ciência Florestal) - Universidade Federal de Viçosa, Viçosa, 2006.

EXTREMA. Lei $\mathbf{n}^{\circ} \mathbf{2 . 1 0 0}$, de 21 de dezembro de 2005. Cria o projeto conservador das águas, autoriza o executivo a prestar apoio financeiro aos proprietários rurais e dá outras providências. Extrema: Prefeitura Municipal de Extrema, 2005.

HARRISON, G. W. Experimental evidence on alternative environmental valuation methods. Environmental \& Resource Economics, New York, v. 34, p. 125-162, 2006.

INSTITUTO MINEIRO DE GESTÃO DAS ÁGUAS. Monitoramento da qualidade das águas superficais na Bacia do Rio Doce em 2007. Belo Horizonte, 2008. 171 p.

LOPES, A. da S.; CASALINHO, H. D. Estratégias para a transição agroecológica. Revista Brasileira de Agroecologia, Porto Alegre, v. 2, n. 2, p. 308-311, 2007.
MARQUES, J. F.; COMUNE, A. E. A teoria neoclássica e a valoração ambiental. In: ROMEIRO, A. R. et al. Economia do meio ambiente: teoria, políticas e a gestão de espaços regionais. Campinas: Unicamp, 1997. 384 p.

MARTINS, R. C.; VALENCIO, N. F. L. da S. Valoração dos recursos hídricos e impasse sócio-ambiental na agricultura paulista: alguns desafios para a gestão de políticas públicas. Informações Econômicas, São Paulo, v. 33, n. 10, out. 2003.

MATTOS, A. D. M.; JACOVINE, L. A. G.; VALVERDE, S. R.; SOUZA, A. L. de; SILVA, M. L. da; LIMA, J. E. de. Valoração ambiental de áreas de preservação permanente da microbacia do ribeirão São Bartolomeu no Município de Viçosa, MG. Revista Árvore, Viçosa, v. 31, n. 2, 2007.

MATTOS, K. M. da C.; MATTOS, K. M. da C.; MATTOS, A. Valoração econômica do meio ambiente dentro do contexto do desenvolvimento sustentável. Revista Gestão Industrial. Ponta Grossa, v. 1, n. 2, p. 105-117, 2005.

PINTO, L. V. A.; BOTELHO, S. A.; DAVIDE, A. C.; FERREIRA, E. Estudo das nascentes da bacia hidrográfica do Ribeirão Santa Cruz, Lavras, MG. Scientia Forestalis, n. 65, p. 197-206, jun. 2004.

SILVA, R. G. da; LIMA, J. E. de. Valoração contingente do parque "Chico Mendes": uma aplicação probabilística do método Referendum com bidding games. Revista de Economia e Sociologia Rural, Brasília, v. 42, n. 4, out./dez. 2004. 
